American Journal of Applied Sciences 7 (2): 235-240, 2010

ISSN 1546-9239

(C) 2010 Science Publications

\title{
Applying Model Reference Adaptive Controller for Lateral Motion of Aircraft
}

\author{
${ }^{1}$ Abdelkader Maddi, ${ }^{1}$ Abderrezak Guesssoum and ${ }^{2}$ Daoued Berkani \\ ${ }^{1}$ LATSI Laboratory, Department of Electronics, University of Blida, \\ Road of Soumaa, PB 270, Blida, Algeria \\ ${ }^{2}$ Department of Electrical Engineering, Polytechnic School of El Harrach, \\ Road of Hassan Badi, PB 182, Algiers, Algeria
}

\begin{abstract}
Problem statement: This study developed a new application for the output model reference adaptive control of linear continuous systems based on the concepts of hyper-stability. Approach: The main idea is to design a non-linear controller which will ensure the minimal error between the reference model and the plant outputs. Results: Therefore, the synthesis of adaptive control with a model of reference was done either using the theory of Lyapunov or from the concept of hyperstability. The proposed approach was developed and applied to a lateral motion of aircraft, in order to determine the lateral and directional control angles required for trim under steady turns and sideslips. Also, this application is based on the directional and lateral static stability derivatives of the aircraft. Conclusion/Recommendations: Simulation results showed the effectiveness of the proposed application method.
\end{abstract}

Keywords: Model reference, adaptive control, robustness, hyper-stability, lateral motion, aircraft

\section{INTRODUCTION}

The Model Reference Adaptive Control (MRAC) was originally proposed to solve a problem in which the performance specifications are given in terms of a reference model (Hafizah et al., 2008). The mechanism for adjusting the parameters in MRAC is usually obtained by using a gradient method or by applying different stability theories.

Popov introduced the notion of hyper-stability in control theory and showed that a linear time-invariant system is asymptotically hyper-stable if and only if the transfer function of system is strictly positive real (Jumarie, 1979). The hyper-stability theory is first, applied to applications in control systems and adapted into the adaptive digital signal processing applications by Landau. The study of this problem is motivated (Xu et al., 2003) by robust and non-linear control in which a wellknown fact is that the positive realness of a certain loop transfer function will guarantee the overall stability of a feedback system if uncertainty or non-linearity can be characterized by a positive real system.

The purpose of this study is to introduce the design of MRAC using the concept of hyper-stability to create a closed loop controller with parameters that can be updated to change the response of the system in the Multiple Input and Multiple Output (MIMO) case. The output of the system is compared to a desired response from a reference model. For example, you may be trying to control the lateral motion of aircraft. Using MRAC, you could choose a reference model that responds quickly to a step input and make the aircraft move just like the model (Gonzalez Blazquez, 1990; Omran and Newman, 2009).

\section{MATERIALS AND METHODS}

The objective of this study is to design a non-linear controller based on the concepts of hyper-stability. Two laws of control which synthesize the signal adaptation, the proportional law control $(\mathrm{P})$ ensures a limited error between the reference model and the plant, have been considered. To eliminate some of these undesirable phenomena, we suggested the use of proportional integrator law control (PI) based on hyper-stability approach that is dominantly rich to eliminate the steady shift error. This approach of Model Reference Adaptive Control is implemented on a computer PC. The performances of the proposed MRAC are applied to a lateral motion of aircraft, in order to determine the lateral and directional control angles required for trim under steady turns and sideslips.

Synthesis of model reference adaptive control: Let us consider a linear plant described by the following equations (Jumarie, 1979):

Corresponding Author: Abdelkader Maddi, LATSI Laboratory, Department of Electronics, University of Blida, Road of Soumaa, PB 270, Blida, Algeria 
$\dot{\mathrm{X}}_{\mathrm{p}}=\mathrm{A}_{\mathrm{p}} \mathrm{X}_{\mathrm{p}}+\mathrm{B}_{\mathrm{p}} \mathrm{U}_{\mathrm{p}}$

$\mathrm{Y}_{\mathrm{p}}=\mathrm{C}_{\mathrm{p}} \mathrm{X}_{\mathrm{p}}$

Where:

$\mathrm{A}_{\mathrm{p}} \quad=$ The $\mathrm{n} \times \mathrm{n}$ matrix

$\mathrm{B}_{\mathrm{p}} \quad=$ The $\mathrm{n} \times \mathrm{m}$ input matrix

$\mathrm{X}_{\mathrm{p}} \quad=$ The $\mathrm{n}$-dimensional state vector

$\mathrm{U}_{\mathrm{p}} \quad=$ The m-dimensional control input vector

$\mathrm{Y}_{\mathrm{p}}$ and $\mathrm{C}_{\mathrm{p}}=$ The output vector and plant output matrix, respectively, each having appropriate dimensions

A linear system with the same number of states, inputs and outputs is selected as reference model having the following form:

$\dot{\mathrm{X}}_{\mathrm{m}}=\mathrm{A}_{\mathrm{m}} \mathrm{X}_{\mathrm{m}}+\mathrm{B}_{\mathrm{m}} \mathrm{U}_{\mathrm{m}}$

$\mathrm{Y}_{\mathrm{m}}=\mathrm{C}_{\mathrm{m}} \mathrm{X}_{\mathrm{m}}$

where, $A_{m}$ and $B_{m}$ are $n \times n$ and $n \times m$ constant matrices respectively.

The error vector $\mathrm{X}_{\mathrm{e}}$, can be defined as:

$\mathrm{X}_{\mathrm{e}}=\mathrm{X}_{\mathrm{m}}-\mathrm{X}_{\mathrm{p}}$

Using some mathematical manipulations, the error equation becomes:

$\dot{\mathrm{X}}_{\mathrm{e}}=\mathrm{A}_{\mathrm{m}} \mathrm{X}_{\mathrm{e}}+\left(\mathrm{A}_{\mathrm{m}}-\mathrm{A}_{\mathrm{p}}\right) \mathrm{X}_{\mathrm{p}}+\mathrm{B}_{\mathrm{m}} \mathrm{U}_{\mathrm{m}}-\mathrm{B}_{\mathrm{p}} \mathrm{U}_{\mathrm{p}}$

The basic structure of Model Reference Adaptive Control (MRAC) scheme is shown in Fig. 1. The reference model is chosen to generate the desired trajectory $Y_{m}$ that the plant output $Y_{p}$ has to follow.

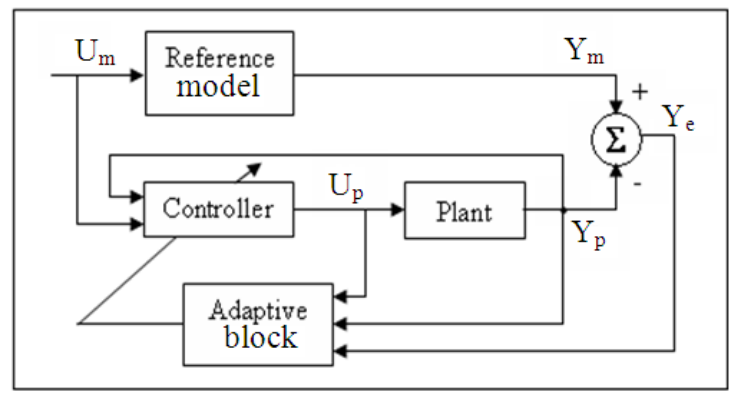

Fig. 1: General structure of a Model Reference Adaptive Control (MRAC)
MRAC schemes can be characterized as direct or indirect adaptive laws. In direct method, the parameter vector of the controller is updated directly by an adaptive law, whereas in indirect method is calculated at each time $\mathrm{t}$ by using on line estimates of the plant parameters (Mitic, 1997). This design procedure allows the use of a wide class of adaptive laws that includes Gradient, Least Squares method and those based on the Lyapunov design approach or from the concept of hyper-stability. This study focuses on the last method to the synthesis of adaptive control systems.

Using Erzerberger conditions (Stoten and Benchoubane, 1990):

$A_{m}-A_{p}=B_{p} B_{p}^{\diamond}\left(A_{m}-A_{p}\right)$

$\mathrm{B}_{\mathrm{m}}=\mathrm{B}_{\mathrm{p}} \mathrm{B}_{\mathrm{p}}^{\diamond} \mathrm{B}_{\mathrm{m}}$

where, $B_{p}^{\diamond}=\left(B_{p}^{T} B_{p}\right)^{-1} B_{p}^{T}$ : Pseudo-inverse left of Penrose.

By substituting the Eq. 7 and 8 in the Eq. 6, we get:

$\dot{\mathrm{X}}_{\mathrm{e}}=\mathrm{A}_{\mathrm{m}} \mathrm{X}_{\mathrm{e}}-\mathrm{B}_{\mathrm{p}} \Phi$

Where:

$\Phi=\mathrm{B}_{\mathrm{p}}^{\diamond}\left(\mathrm{A}_{\mathrm{p}}-\mathrm{A}_{\mathrm{m}}\right) \mathrm{X}_{\mathrm{p}}-\mathrm{B}_{\mathrm{p}}^{\diamond} \mathrm{B}_{\mathrm{m}} \mathrm{U}_{\mathrm{m}}+\mathrm{U}_{\mathrm{p}}$

A stability proof for these controllers to choose the variable elements of linear system so that its transfer function is strictly positive real and the block of negative feedback with non-linear characteristic satisfies the Popov inequality for hyper-stability. Using Eq. 5 and 9, we obtain the following system:

$\dot{\mathrm{X}}_{\mathrm{e}}=\mathrm{A}_{\mathrm{m}} \mathrm{X}_{\mathrm{e}}-\mathrm{B}_{\mathrm{p}} \Phi$

$\mathrm{Y}_{\mathrm{e}}=\mathrm{C}_{\mathrm{e}} \mathrm{X}_{\mathrm{e}}$

The system described by Eq.11and 12 can be represented in a block diagram of Fig. 2 .

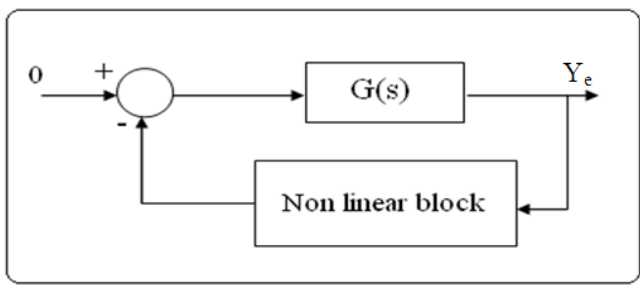

Fig. 2: Block diagram of hyper-stable system 
Proportional form (P): Let us consider the feedback control law:

$$
\mathrm{U}_{\mathrm{p}}=\mathrm{K}_{\mathrm{x}} \mathrm{X}_{\mathrm{p}}+\mathrm{K}_{\mathrm{u}} \mathrm{U}_{\mathrm{m}}
$$

The inequality of Popov is applied (Jumarie, 1979; Rao and Hassan, 2004):

$$
\eta\left(\mathrm{t}_{0}, \mathrm{t}_{1}\right)=\int_{\mathrm{t}_{0}}^{\mathrm{t}_{1}} \Phi^{\mathrm{T}}\left(\mathrm{Y}_{\mathrm{e}}\right) \mathrm{Y}_{\mathrm{e}} \mathrm{dt} \geq-\gamma_{0}^{2}
$$

Where:

$\gamma_{0}^{2}=$ Positive constant independent of $\mathrm{t}$

$\mathrm{Y}_{\mathrm{e}}=$ Input of non-linear block

$\Phi=$ Output of non-linear block

By replacing the Eq. 10 in the 14, we obtain the following equation:

$$
\begin{aligned}
\eta\left(\mathrm{t}_{0}, \mathrm{t}_{1}\right)= & \int_{\mathrm{t}_{0}}^{\mathrm{t}_{\mathrm{t}}}\left\{\left[\mathrm{K}_{\mathrm{x}}-\mathrm{B}_{\mathrm{p}}^{\diamond}\left(\mathrm{A}_{\mathrm{m}}-\mathrm{A}_{\mathrm{p}}\right)\right] \mathrm{X}_{\mathrm{p}}\right. \\
& \left.+\left(\mathrm{K}_{\mathrm{u}}-\mathrm{B}_{\mathrm{p}}^{\diamond} \mathrm{B}_{\mathrm{m}}\right) \mathrm{U}_{\mathrm{m}}\right\}^{\mathrm{T}} \mathrm{Y}_{\mathrm{e}} \mathrm{dt} \geq-\gamma_{0}^{2}
\end{aligned}
$$

A solution that satisfies the hyper-stability condition for $\mathrm{K}_{\mathrm{x}}$ and $\mathrm{K}_{\mathrm{u}}$ is:

$$
\begin{aligned}
& {\left[\mathrm{K}_{\mathrm{x}}-\mathrm{B}_{\mathrm{p}}^{\diamond}\left(\mathrm{A}_{\mathrm{m}}-\mathrm{A}_{\mathrm{p}}\right)\right]^{\mathrm{T}}=\alpha_{1}\left(\mathrm{X}_{\mathrm{p}} \mathrm{Y}_{\mathrm{e}}^{\mathrm{T}}\right)^{2 \mathrm{~N}+1}} \\
& {\left[\mathrm{~K}_{\mathrm{u}}-\mathrm{B}_{\mathrm{p}}^{\diamond} \mathrm{B}_{\mathrm{m}}\right]^{\mathrm{T}}=\beta_{1}\left(\mathrm{U}_{\mathrm{m}} \mathrm{Y}_{\mathrm{e}}^{\mathrm{T}}\right)^{2 \mathrm{~N}+1}}
\end{aligned}
$$

where, $\alpha_{1}$ and $\beta_{1}$ are two strictly positive matrices with dimension $\mathrm{n} \times \mathrm{n}$ and $\mathrm{n} \times \mathrm{m}$ respectively.

If $\mathrm{N}=0$, then $\mathrm{K}_{\mathrm{x}}$ and $\mathrm{K}_{\mathrm{u}}$ can be written as follow:

$\mathrm{K}_{\mathrm{x}}=\mathrm{B}_{\mathrm{p}}^{\diamond}\left(\mathrm{A}_{\mathrm{m}}-\mathrm{A}_{\mathrm{p}}\right)+\mathrm{Y}_{\mathrm{e}} \mathrm{X}_{\mathrm{p}}^{\mathrm{T}} \alpha_{1}{ }^{\mathrm{T}}$

$\mathrm{K}_{\mathrm{u}}=\mathrm{B}_{\mathrm{p}}^{\diamond} \mathrm{B}_{\mathrm{m}}+\mathrm{Y}_{\mathrm{e}} \mathrm{U}_{\mathrm{m}}^{\mathrm{T}} \beta_{1}^{\mathrm{T}}$

Proportional Integrator form (PI): We define the law control $\mathrm{U}_{\mathrm{p}}$ as (Yang et al., 2006):

$\mathrm{U}_{\mathrm{p}}=\mathrm{K}_{\mathrm{r}} \mathrm{r}=\left[\mathrm{K}_{\mathrm{x}}, \mathrm{K}_{\mathrm{u}}\right]\left[\mathrm{X}_{\mathrm{p}}, \mathrm{U}_{\mathrm{m}}\right]^{\mathrm{T}}$

Where:

$$
\mathrm{K}_{\mathrm{r}}=\mathrm{K}_{\mathrm{p}}+\mathrm{K}_{\mathrm{i}}
$$

With:

$$
\begin{aligned}
& \mathrm{K}_{\mathrm{p}}=\mathrm{Y}_{\mathrm{e}} \mathrm{r}^{\mathrm{T}} \beta_{2} \\
& \dot{\mathrm{K}}_{\mathrm{i}}=\mathrm{Y}_{\mathrm{e}} \mathrm{r}^{\mathrm{T}} \alpha_{2}
\end{aligned}
$$

$\mathrm{K}_{\mathrm{i}}(0)=\mathrm{K}_{\mathrm{i} 0}$

$\mathrm{Y}_{\mathrm{e}}=\mathrm{C}_{\mathrm{e}}\left(\mathrm{X}_{\mathrm{m}}-\mathrm{X}_{\mathrm{p}}\right)$

Where:

$\alpha_{2}$ and $\beta_{2}=$ Adaptive control weightings

$\mathrm{K}_{\mathrm{i} 0} \quad=$ The initial value of integration gain

In general the initial gain values can be set to zero such that the controller requires no knowledge of the plant parameters $A_{p}$ and $B_{p}$. The adaptive weightings, $\alpha_{2}$ and $\beta_{2}$ need to be selected in advance and clearly have a significant influence on the rate of adaptation as they act as fixed gain values which multiply the proportional and integral parts of the controller gain.

The Eq.10 can thus be written in vector form:

$\Phi=\left(\mathrm{L}_{\mathrm{r}}+\mathrm{K}_{\mathrm{r}}\right) \mathrm{r}$

Where

$\mathrm{K}_{\mathrm{r}}=\left[\mathrm{K}_{\mathrm{x}}, \mathrm{K}_{\mathrm{u}}\right]$

$\mathrm{L}_{\mathrm{r}}=\left[\mathrm{B}_{\mathrm{p}}^{\diamond}\left(\mathrm{A}_{\mathrm{p}}-\mathrm{A}_{\mathrm{m}}\right),-\mathrm{B}_{\mathrm{p}}^{\diamond} \mathrm{B}_{\mathrm{m}}\right]$

Applying the criterion of Popov, we obtain:

$\eta\left(t_{0}, t_{1}\right)=\int_{t_{0}}^{t_{t}}\left[\left(L_{r}+K_{r}\right) r\right]^{T} Y_{e} d t \geq-\gamma_{0}^{2}$

By replacing Eq. 21-24 and 25 in 27, the latter will thus be written:

$$
\begin{aligned}
\eta\left(\mathrm{t}_{0}, \mathrm{t}_{1}\right)= & \int_{\mathrm{t}_{0}}^{\mathrm{t}_{1}} \mathrm{r}^{\mathrm{T}}\left[\mathrm{L}_{\mathrm{r}}^{\mathrm{T}}+\int_{0}^{\mathrm{t}} \mathrm{Y}_{\mathrm{e}} \mathrm{r}^{\mathrm{T}} \alpha_{2} \mathrm{~d} \tau\right]^{\mathrm{T}} \mathrm{Y}_{\mathrm{e}} \mathrm{dt}+ \\
& \int_{\mathrm{t}_{0}}^{\mathrm{t}_{1}} \mathrm{r}^{\mathrm{T}} \beta_{2}{ }^{\mathrm{T}} \mathrm{r} Y_{\mathrm{e}}^{\mathrm{T}} \mathrm{Y}_{\mathrm{e}} \mathrm{dt} \geq-\gamma_{0}^{2}
\end{aligned}
$$

It is clear from (Eq. 28), a solution that satisfies the hyper-stability condition for $\alpha_{2}$ and $\beta_{2}$ is:

$$
\begin{gathered}
\alpha_{2}{ }^{\mathrm{T}}>0 \\
\beta_{2}{ }^{\mathrm{T}} \geq 0
\end{gathered}
$$


Am. J. Applied Sci., 7 (2): 235-240, 2010

Table 1: Geometric characteristics

\begin{tabular}{ll}
\hline Description & Values for CESSNA-182 \\
\hline Wing area & $174.00 \mathrm{sq} . \mathrm{ft}$ \\
Wight & $2645.00 \mathrm{Ibs}$ \\
Wing span & $35.80 \mathrm{ft}$ \\
Mean aerody. chord & $4.90 \mathrm{ft}$ \\
Air speed & $219.00 \mathrm{ft} / \mathrm{sec}$ \\
Air density & 0.00205 slugs $/ \mathrm{cu} . \mathrm{ft}$ \\
Initial theta & $0.00 \mathrm{rad}$ \\
High & $5000 \mathrm{ft}$ \\
$\mathrm{I}_{\mathrm{yy}}$ & 1346 slugs. sq. ft \\
$\mathrm{I}_{\mathrm{xx}}$ & 948 slugs. sq. $\mathrm{ft}$ \\
$\mathrm{I}_{\mathrm{zz}}$ & 1967 slugs. sq. $\mathrm{ft}$ \\
$\mathrm{I}_{\mathrm{xz}}$ & 0.00 slugs. sq. $\mathrm{ft}$ \\
$\mathrm{x}_{\mathrm{cg}}$ & 0.25 \\
\hline
\end{tabular}

Table 2: Lateral factors of stability

\begin{tabular}{|c|c|}
\hline Quantity & Values for CESSNA-182 \\
\hline $\mathrm{L}_{\beta}$ & $-28.7492 / \mathrm{rad} . \mathrm{sec}^{2}$ \\
\hline $\mathrm{L}_{\mathrm{p}}$ & $-12.4092 / \mathrm{rad} . \mathrm{sec}$ \\
\hline $\mathrm{L}_{\mathrm{r}}$ & $2.5346 / \mathrm{rad} . \mathrm{sec}$ \\
\hline $\mathrm{L}_{\delta \mathrm{a}}$ & $57.4984 / \mathrm{rad} . \mathrm{sec}^{2}$ \\
\hline $\mathrm{L}_{\delta \mathrm{r}}$ & $4.7485 / \mathrm{rad} . \mathrm{sec}^{2}$ \\
\hline $\mathrm{N}_{\beta}$ & $10.1194 / \mathrm{rad} . \mathrm{sec}^{2}$ \\
\hline $\mathrm{N}_{\mathrm{p}}$ & $-0.3817 / \mathrm{rad} . \mathrm{sec}$ \\
\hline $\mathrm{N}_{\mathrm{r}}$ & $-1.2597 / \mathrm{rad} . \mathrm{sec}$ \\
\hline $\mathrm{N}_{\delta \mathrm{a}}$ & $-8.2512 / \mathrm{rad} . \mathrm{sec}^{2}$ \\
\hline $\mathrm{L}_{\delta \mathrm{r}}$ & $-10.2284 / \mathrm{rad} . \mathrm{sec}^{2}$ \\
\hline $\mathrm{Y}_{\beta}$ & $-32.2554 \mathrm{ft} / \mathrm{rad} . \mathrm{sec}^{2}$ \\
\hline$Y_{p}$ & $-0.3147 \mathrm{ft} / \mathrm{rad} . \mathrm{sec}$ \\
\hline $\mathrm{Y}_{\mathrm{r}}$ & $1.7859 \mathrm{ft} / \mathrm{rad} . \mathrm{sec}$ \\
\hline $\mathrm{Y}_{\delta \mathrm{a}}$ & $0.0000 \mathrm{ft} / \mathrm{rad} . \mathrm{sec}^{2}$ \\
\hline $\mathrm{Y}_{\delta \mathrm{r}}$ & $19.4730 \mathrm{ft} / \mathrm{rad} . \mathrm{sec}^{2}$ \\
\hline
\end{tabular}

Application to CESSNA-182 aircraft: The CESSNA182 was introduced in 1956, as a tricycle gear variant of the 180. The characteristics of CESSNA-182 are presented (Maddi et al., 2009) on Table 1 and having the following lateral factors of stability represented on Table 2.

The rigid body equations of motion are the differential equations that describe the evolution of the basic states of an aircraft. These equations of motion are all non-linear first order ordinary differential equations. In addition they are highly coupled, i.e., each differential equation depends upon variables.

However, we may gain some insight into the equations of motion by examining in steady state solutions, which then are in the matrix form:

$$
\dot{\mathrm{X}}_{\mathrm{p}}=\mathrm{A}_{\mathrm{p}} \mathrm{X}_{\mathrm{p}}+\mathrm{B}_{\mathrm{p}} \mathrm{U}_{\mathrm{p}}
$$

Where

$\delta_{\mathrm{a}}, \delta_{\mathrm{r}}=$ Aileron and rudder deflection

$\beta, \phi=$ Sideslip and roll angle

$\mathrm{p}, \mathrm{r}=$ Roll and yaw rate

$$
\begin{aligned}
& \mathrm{X}_{\mathrm{p}}^{\mathrm{T}}=\left[\begin{array}{llll}
\beta & \mathrm{p} & \mathrm{r} & \varphi
\end{array}\right], \mathrm{U}_{\mathrm{p}}^{\mathrm{T}}=\left[\begin{array}{ll}
\delta_{\mathrm{a}} & \delta_{\mathrm{r}}
\end{array}\right]
\end{aligned}
$$

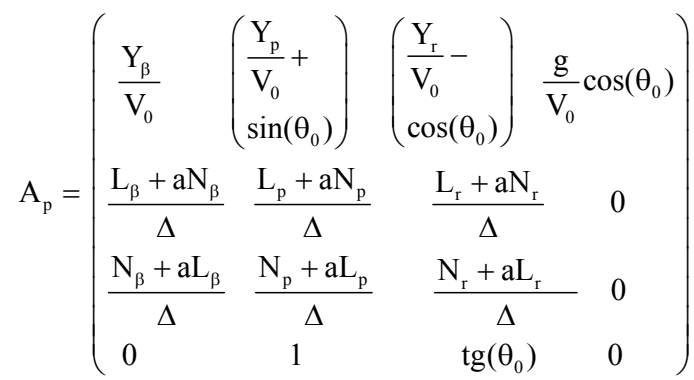

$$
\begin{aligned}
& \mathrm{B}_{\mathrm{p}}=\left(\begin{array}{ll}
\frac{\mathrm{Y}_{\delta \mathrm{r}}}{\mathrm{V}_{0}} & \frac{\mathrm{Y}_{\delta \mathrm{a}}}{\mathrm{V}_{0}} \\
\frac{\mathrm{L}_{\delta \mathrm{r}}+\mathrm{aN}_{\delta \mathrm{r}}}{\Delta} & \frac{\mathrm{L}_{\delta \mathrm{a}}+\mathrm{aN}_{\delta \mathrm{a}}}{\Delta} \\
\frac{\mathrm{N}_{\delta \mathrm{r}}+\mathrm{bL}_{\delta \mathrm{r}}}{\Delta} & \frac{\mathrm{N}_{\delta \mathrm{a}}+\mathrm{bL}_{\delta \mathrm{a}}}{\Delta} \\
0 & 0
\end{array}\right)
\end{aligned}
$$

Where:

$\mathrm{a}=\frac{\mathrm{I}_{\mathrm{xz}}}{\mathrm{I}_{\mathrm{xx}}}$

$\mathrm{b}=\frac{\mathrm{I}_{\mathrm{xz}}}{\mathrm{I}_{\mathrm{zz}}}$

$\Delta=1-\mathrm{a} \times \mathrm{b}$

\section{RESULTS}

The reference model of an aircraft (Maddi et al., 2009) is selected according to three criteria:

- The state matrix $A_{m}$ is negative defined to ensure the stability and the handiness of the aircraft in the same time

- A sideslip angle $\beta$ induced by the ailerons is null, to ensure a correct turn

- A roll angle $\phi$ induced by the rudders is negative to improve a static stability

By respecting the criteria quoted above, the matrices parameters of the state equation describing the following model $\dot{\mathrm{X}}_{\mathrm{m}}=\mathrm{A}_{\mathrm{m}} \mathrm{X}_{\mathrm{m}}+\mathrm{B}_{\mathrm{m}} \mathrm{U}_{\mathrm{m}}$ that we will use all along our study (Datta and Ioannou, 1994), will be equal to:

$$
\mathrm{A}_{\mathrm{m}}=\left[\begin{array}{rccc}
-0.7 & 0 & -1 & 0 \\
-10 & -10 & 0 & 0 \\
9 & 0 & -0.7 & 0 \\
0 & 1 & 0 & 0
\end{array}\right] \quad \mathrm{B}_{\mathrm{m}}=\left[\begin{array}{cc}
0 & 0 \\
9.82 & 1.01 \\
-9.49 & 0 \\
0 & 0
\end{array}\right]
$$



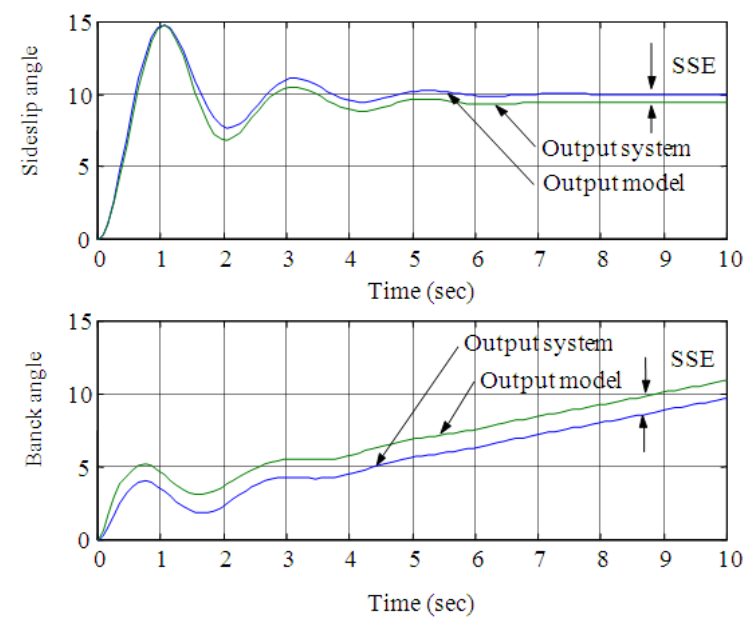

Fig. 3: Time response of sideslip angle and roll angle in case Proportional law control (P)
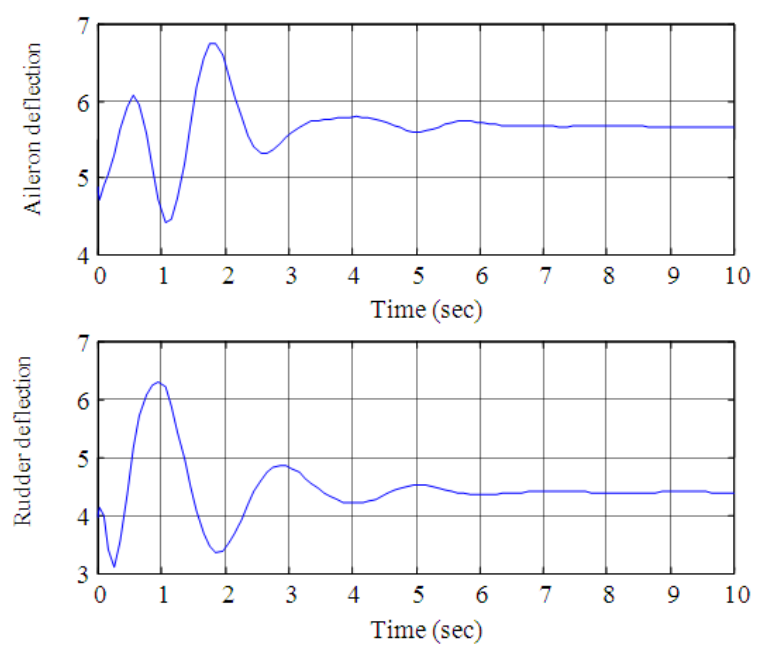

Fig. 4: Time response of aileron deflection and rudder deflection in case Proportional law control (P)

Simulation results are shown in Fig. 3-6 where we show the time responses of the output system $Y_{p}$, the output reference model $\mathrm{Y}_{\mathrm{m}}$ and the control $\mathrm{U}_{\mathrm{p}}$ for $\mathrm{P}$ and PI law control.

\section{DISCUSSION}

From Fig. 3 and 5, it is clear that, with $\alpha_{2}=0.01 \mathrm{I}_{2 \times 2}$ and $\beta_{2}=0.01 \mathrm{I}_{2 \times 2}$, the case of Proportional Integrator law control (PI) gives a better transient performance as compared to the Proportional law control (P). The value of Steady Shift Error (SSE) was then further reduced to zero and the control signals are little smooth as shown in Fig. 4 and 6.
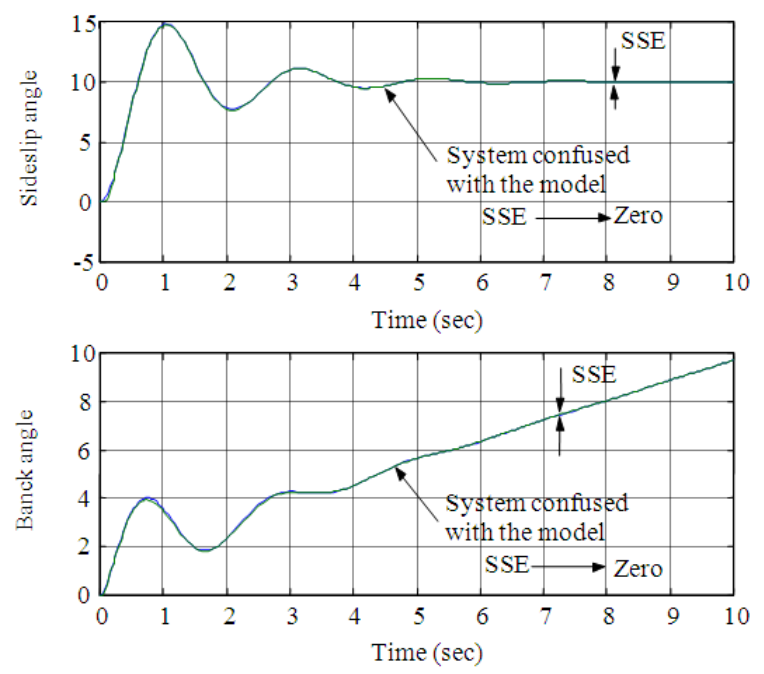

Fig. 5: Time response of sideslip angle and roll angle in case Proportional Integrator law control (PI)
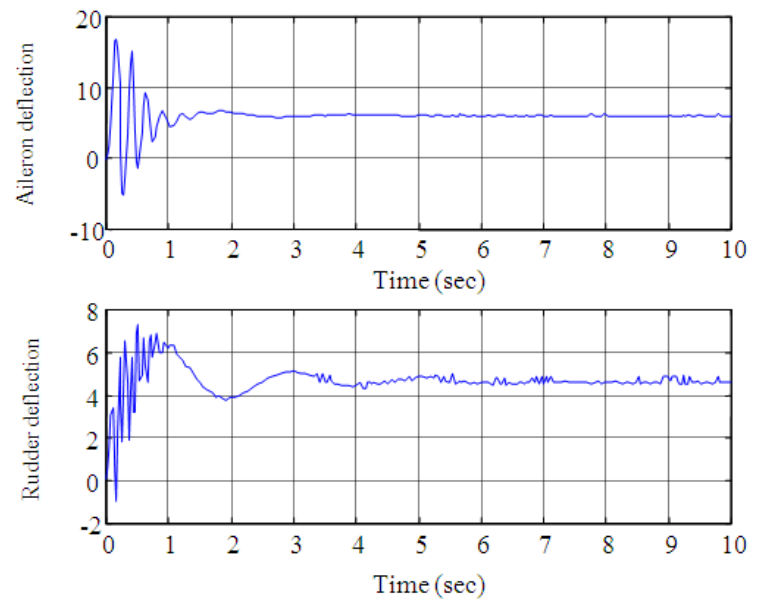

Fig. 6: Time response of aileron deflection and rudder deflection in case Proportional Integrator law control (PI)

This confirms our observation that, in the PI case law control, the SSE cannot be chosen to be too small or else instability of the control signals will result, which do not meet any more the characteristics of the control surfaces of aircraft.

\section{CONCLUSION}

The Model Reference Adaptive Control (MRAC) knew many industrial applications and especially in the field of aeronautics. Indeed, the convergence of such algorithms is related to a condition of positivity relating to either a matrix or a transfer function. 
An application to lateral motion of aircraft was presented to show that phenomena such as a limited steady shift error could occur. To eliminate some of the undesirable phenomena, we suggested the use of proportional integrator law control based on hyperstability approach that is dominantly rich to eliminate the SSE. This law control is shown to guaranty a good convergence to the following model.

Finally, the MRAC gives a very good following of the reference model with a steady shift error limited. The control signals are little smooth except in the PI law control, it appears oscillations, which do not meet any more the characteristics of the control surfaces of aircraft, from where we need the other class of control.

The extension of a proposed method to the design of model reference adaptive controller for disturbed systems is a current research topic.

\section{REFERENCES}

Datta, A. and P.A. Ioannou, 1994. Performance analysis and improvement in model reference adaptive control. IEEE Trans. Automat. Control, 39: 2370-2381. hppt://www-

rcf.usc.edu/ ioannou/2003update/d39.pdf

Gonzalez Blazquez, A.L., 1990. Mathematical modeling for analysis of non-linear aircraft dynamics. Comput. Struct., 37: 193-197. DOI: 10.1016/0045-7949(90)90401-M

Husain, H., M. Khalid and R. Yusof, 2008. Direct model reference adaptive controller based-on neural-fuzzy techniques for non-linear dynamical systems. Am. J. Applied Sci., 5: 769-776. http://www.scipub.org/fulltext/ajas/ajas57769776.pdf

Jumarie, G., 1979. Hyperstability and average hyperstability conditions for a broad class of Gaussian stochastic systems. Inform. Sci., 17: 23-41. DOI: 10.1016/0020-0255(79)90041-0
Maddi, A., A. Guessoum and D. Berkani, 2009. Using linear quadratic gaussian optimal control for lateral motion of aircraft. Proc. World Acad. Sci. Eng. Technol., $\quad 37$ 285-289. http://www.waset.org/journals/waset/v49/v4956.pdf

Mitic, D., 1997. Variable structure model reference adaptive systems with proportional-plus-integral action. Sci. J. FACTA Univ., 2: 315-324. http://facta.junis.ni.ac.rs/macar/macar97/macar9712.pdf

Omran, A. and B. Newman, 2009. Piecewise global volterra non-linear modeling and characterization for aircraft dynamics. J. Guidance, Control Dyn., 32: 749-759. DOI: $10.2514 / 1.40655$

Rao, M.P.R.V. and H.A. Hassan, 2004. New adaptive laws for model reference adaptive control using non-quadratic Lyapunov functions. AUTOMATIKA: J. Control, Measure. Elect. Comput. Commun., 45: 155-159. http://hrcak.srce.hr/index.php?lang=en\&show=clan ak\&id_clanak_jezik $=10286$

Stoten, D.P. and H. Benchoubane, 1990. Empirical studies of an MRAC algorithm with minimal controller synthesis. Int. J. Control, 51: 823-849. http://cat.inist.fr/?aModele $=$ afficheN\&cpsidt $=6930$ 424

Xu, S., J. Lam, Z. Lin, K. Galkowski and W. Paszke et al., 2003. Positive real control of two dimensional systems: Roesser models and linear repetitive processes. Int. J. Control, 76: 1047-1058. http://eprints.ecs.soton.ac.uk/7468/1/pdr.pdf

Yang, L., S.A. Neild, D.J. Wagg and D.W. Virden, 2006. Model reference adaptive control of a nonsmooth dynamical system. Non-linear Dyn., 46: 323-335. DOI: 10.1007/s11071-006-9048-6 